\title{
A review of the role of ultrasound biomicroscopy in glaucoma associated with rare diseases of the anterior segment
}

This article was published in the following Dove Press journal:

Clinical Ophthalmology

29 July 2016

Number of times this article has been viewed

\section{Giuseppe Mannino' \\ Barmak Abdolrahimzadeh ${ }^{2}$ \\ Silvia Calafiore \\ Gianmario Anselmi' \\ Cristina Mannino' \\ Alessandro Lambiase ${ }^{3}$ \\ 'Ophthalmology Unit, Saint Andrea Hospital, Department of Neurosciences, Mental Health and Sense Organs, University of Rome "Sapienza", Rome, Italy; ${ }^{2}$ Polimed Beltramelli Medical Centre, Rome, Italy; ${ }^{3}$ Department of Sense Organs, Ophthalmology Unit, University of Rome "Sapienza", Rome, Italy}

\begin{abstract}
Ultrasound biomicroscopy is a non-invasive imaging technique, which allows high-resolution evaluation of the anatomical features of the anterior segment of the eye regardless of optical media transparency. This technique provides diagnostically significant information in vivo for the cornea, anterior chamber, chamber angle, iris, posterior chamber, zonules, ciliary body, and lens, and is of great value in assessment of the mechanisms of glaucoma onset. The purpose of this paper is to review the use of ultrasound biomicroscopy in the diagnosis and management of rare diseases of the anterior segment such as mesodermal dysgenesis of the neural crest, iridocorneal endothelial syndrome, phakomatoses, and metabolic disorders.
\end{abstract}

Keywords: glaucoma, rare diseases, ultrasound biomicroscopy, neural crest, iridocorneal syndrome, phakomatoses, metabolic disorders

\section{Introduction}

Ultrasound biomicroscopy (UBM) is a high-resolution technique, which allows in vivo assessment of the structures of the anterior segment of the eye. ${ }^{1,2}$ Cross-sectional images of ocular structures are obtained at microscopic resolution. The commercially available transducers used in obtaining high-frequency B-scan ultrasonography images with an immersion technique operate between 35 and $50 \mathrm{MHz}$. Thus, images of the structural features of the ocular anterior segment are obtained to a depth of about $4 \mathrm{~mm}$ and an axial and lateral resolution of approximately 25 and 50 microns, respectively. 3,4

The technique is non-invasive and efficient regardless of the clarity of the optical media and it can be performed in children with no complications. ${ }^{5}$ The internal acoustic characteristics of UBM, aided by the very fine backscatter speckle patterns at the frequencies used, permit differentiation of tissue. ${ }^{2}$ Pathologies behind anterior segment opacities can be imaged in detail with a wide gray scale that provides quantitative and qualitative information. Furthermore, UBM imaging has the capability to define relationships between the various structures of the anterior segment such as anterior chamber and angle, iris, posterior chamber, zonules, ciliary body, and lens, and is very useful in understanding the dynamics behind glaucoma. ${ }^{6-8} \mathrm{UBM}$ visualizes structures, which are not easily accessible by conventional clinical examination and provides valuable additional information on the mechanisms of disease.

Anterior segment optical coherence tomography (AS-OCT) is also used to study anterior segment structures. AS-OCT enables the acquisition of high-resolution crosssectional images using low-coherence interferometry and infrared light, however it is
Correspondence: Alessandro Lambiase Department of Sense Organs, Ophthalmology Unit, University of Rome "Sapienza", viale del Policlinico I55, Rome 00161 , Italy

Email alessandro.lambiase@uniromal.it 
not recommended for the study of the ciliary body because the pigmented layer of the iris does not allow transmission of infrared light. ${ }^{9}$ UBM enables the visualization of the peripheral iris, ciliary body, and even the anterior choroid, and may be used to investigate the mechanisms of angle closure glaucoma in plateau iris, ciliary effusion syndrome, lens subluxation syndrome, and ciliary body cysts and tumors. The drawback of UBM is the necessity of direct contact with the eye as opposed to the non-contact, rapid technique involved in AS-OCT imaging. ${ }^{10}$

This paper is focused on UBM findings in glaucoma occurring in rare diseases with a brief review of the various clinical applications.

\section{Methods of UBM imaging}

We have been involved in UBM imaging since 1996 at the University of Rome "Sapienza" both in the clinical management of patients and in research with an average number of 5,000 examinations. We have studied the UBM features in 48 patients with rare diseases of the anterior segment. We initially operated the Humphrey-Zeiss model 840 (San Leandro, CA, USA) (50 MHz) and presently use the Optikon HiScan Touch (Rome, Italy) (35-50 MHz) UBM system. Our method of examination is as follows: the patient is placed in a supine position and following topical anesthesia with benoxinate hydrochloride $0.4 \%$ drops, the eyelids are held open with a water-filled scleral shell and methylcellulose used as coupling agent. High-frequency scans are taken, radial and parallel to the limbus at various positions. The exam can be easily performed in an office setting and has an approximate duration of 10 minutes per eye. Cooperative children can be examined with this method in an office setting when there is a physician with broad experience with UBM. In case of infants below 2 years of age and uncooperative patients, the examination may have to be performed using general anesthesia in the operating room.

\section{Clinical applications of UBM}

UBM is a valid imaging method for the study of the cornea, anterior chamber, iridocorneal angle, iris, zonules, ciliary body, and the crystalline lens. Pavlin et al and Pavlin and Foster carried out the earliest studies with UBM of the anterior segment in glaucoma to investigate the etiology and mechanisms of disease in different subtypes of glaucoma. ${ }^{6,7}$ There is a large body of literature on UBM applications in glaucoma, where detailed assessment of the anterior segment, and the relationship between the peripheral iris and angle structures have been evaluated.
UBM has been used in the evaluation of cysts of the anterior segment, ciliary body, and the pars plana. Indeed, the entire anterior chamber, and the effect of the iris and/or ciliary body cysts on narrowing of the chamber angle in correspondence to the cysts can be assessed. ${ }^{1-14}$ Furthermore, UBM can measure iris and/or ciliary body cyst dimensions, anterior chamber depth, angle aperture, and trabecular-iris angle. It is also possible to differentiate between cystic and solid formations, and to assess tumor extension. In particular, cysts appear as lesions with a thin cyst wall and no solid components.

Anterior segment tumors can be studied with UBM, which gives valuable information on the extension of pigmented lesions or malignant melanoma from the iris to the ciliary body. ${ }^{6,15-17}$

UBM has also been used in evaluating the cornea in dystrophies, scars, and following excimer laser photokeratectomy and laser in situ keratomileusis. ${ }^{18-21}$ UBM allows evaluation of intraocular lens implants and can detect nuclear fragments behind the iris following complicated cataract surgery. ${ }^{22}$ Furthermore, with the advent of intravitreal injections and steroid implants in various pathologies, it is a useful tool to evaluate complications such as injection or migration of implants in the anterior segment. ${ }^{23-25}$

\section{UBM and glaucoma}

The studies of Pavlin in primary angle closure glaucoma included plateau iris syndrome and pupillary block. ${ }^{6,7}$ Examination of narrow angles in mydriasis induced by scotopic conditions can show possible appositional angle closure. ${ }^{26}$ In glaucoma with pupillary block, the pressure in the posterior chamber is higher compared to the anterior chamber because aqueous humor cannot flow past the pupil. UBM demonstrates bending forward of the entire iris with a clearly visible and well formed posterior chamber. ${ }^{27}$ The mechanism of glaucoma in plateau iris syndrome is shown with UBM as closure of the sulcus and an anterior placement of the ciliary processes. Indeed, in this form of glaucoma the ciliary body is larger and is placed in an anterior position; this causes an impairment of aqueous outflow because of compression of the iridocorneal angle. ${ }^{6} \mathrm{UBM}$ examination in pseudoexfoliation syndrome shows a flattened anterior chamber, and the crystalline lens has been reported to be thicker in affected eyes, most probably due to zonular defects which are shown by UBM as zonular remnants attached to the lens capsule. ${ }^{16,28,29}$ The mechanism of pigmentary glaucoma involves difficulty in trabecular outflow due to dispersion of pigment from the iris. In this condition UBM shows iris 
concavity. In patients with pseudophakia, UBM can help to determine the mechanism of pupillary block glaucoma. UBM is also an important method of imaging in glaucoma surgery and has a central role in the follow-up of patients regarding the filtering bleb and Schlemm's canal. ${ }^{30,31}$

Measurement of the anterior segment structures with UBM is important in classifying various types of angle closure and open angle glaucoma. ${ }^{32}$ Common biometric parameters that are used in describing the anterior chamber are "angle opening index", "angle recess area", "trabeculariris space area", and "trabecular-ciliary process area". ${ }^{33}$ These values aid in the establishment of reproducible values for classifying the various subtypes of glaucoma.

\section{Primary congenital glaucoma}

UBM allows assessment of the anterior segment morphology, and the diagnosis of primary congenital glaucoma can be established, especially in patients with opaque corneas, and in infants younger than 2 years. Clinical features of primary congenital glaucoma include: increased axial length, thin cornea with larger diameter, deep anterior chamber, narrow posterior chamber, reduced iris thickness, wide anterior chamber angle, absence of iris crypts, possible anterior iris insertion or abnormal angle membrane, and ciliary process abnormalities. ${ }^{34-38}$ UBM usually reveals the absence of iris crypts, which is probably caused by lack of iris sphincter and dilator muscle, although uveal and neuroepithelial layers are preserved. ${ }^{39}$ UBM can also demonstrate elongated and tight ciliary processes near the posterior surface of the iris, sometimes occluding the ciliary sulcus. At times a thin hyperreflective membrane that covers angle structures can be visible (Barkan's membrane). ${ }^{40}$

Secondary glaucoma can be a complication of an array of rare diseases classified in the following groups: conditions with mesodermal dysgenesis of the neural crest, iridocorneal endothelial (ICE) syndrome, phakomatoses, and metabolic disorders. In these cases UBM can play an important role in identifying the anterior segment alterations associated with glaucoma. ${ }^{41}$

\section{Glaucoma in mesodermal dysgenesis of the neural crest}

The migration of neural crest cells leads to the formation of many structural components of the ocular anterior segment, including corneal endothelium, keratocytes, iris stroma, melanocytes, and the trabecular meshwork. ${ }^{42}$ Thus, an abnormal maturation of neuroectodermal cells can lead to various syndromes involving the anterior segment. The Axenfeld-Rieger anomaly, Peter's anomaly, iris hypoplasia or aniridia, and congenital glaucoma, can arise due to developmental arrest or an altered migration of neural crest cells at a late stage of pregnancy. ${ }^{42,43}$

Axenfeld-Rieger syndrome is an autosomal-dominant condition associated with mutations of PITX2, FOXC1 shown with genetic analysis. In this syndrome glaucoma is present in $50 \%$ of patients. The pathogenesis is characterized by atypical maturation of neuroectodermal cells but an altered primordial endothelial cell layer causing chamber angle anomalies has also been suggested. ${ }^{41}$ Histological sections have revealed malformations of Schlemm's canal and the trabecular meshwork, these alterations coincide with the UBM features of a prominent or anterior positioned Schwalbe's line. ${ }^{42}$ Other characteristic UBM features seen in this condition are iridocorneal fiber filaments, high insertion of the iris into the posterior part of the trabecular meshwork, peripheral anterior synechiae, and atrophic iris (Figure 1).

Pathogenesis in other conditions such as Peter's anomaly, aniridia or iris hypoplasia, sclerocornea, and megalocornea is linked to an abnormal anterior chamber angle leading to impaired aqueous humor drainage. ${ }^{42}$ Sclerocornea is a rare condition characterized by extension of sclera, conjunctival tissue, and episcleral tissue into the clear cornea, which leads to opacification. Typical findings are hyper-reflectivity of the cornea, flattened cornea with thickening of the peripheral cornea and central posterior excavation caused by involved posterior stroma, Descemet's membrane and endothelium, and an abnormal Bowman's layer which is frequently replaced by irregular hyaline material. A number of histological features are correlated to UBM findings in sclerocornea (Figure 2). ${ }^{6}$

Aniridia can be sporadic or inherited, PAX6 gene mutations have been shown in non-syndromic aniridia with autosomal dominant inheritance and familial occurrence. ${ }^{44-46}$ The typical UBM feature is a bilateral absence of most of the iris

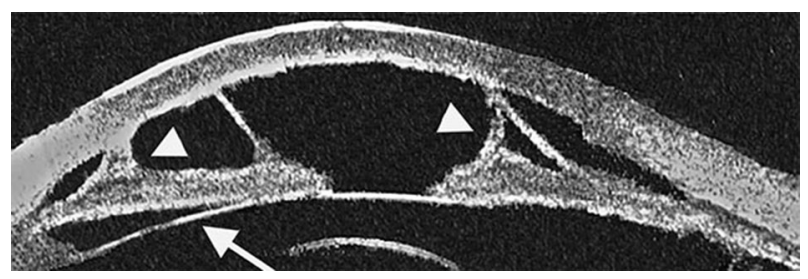

Figure I Ultrasound biomicroscopy image using the Humphrey-Zeiss model 840, (San Leandro, CA, USA [50 MHz]) showing a case of Axenfeld-Rieger anomaly. Notes: The anterior chamber structures present kerato-irido-lenticular contacts. Anterior synechiae are clearly revealed (arrow heads). The ciliary body appears adherent to the posterior iris surface (arrow). 


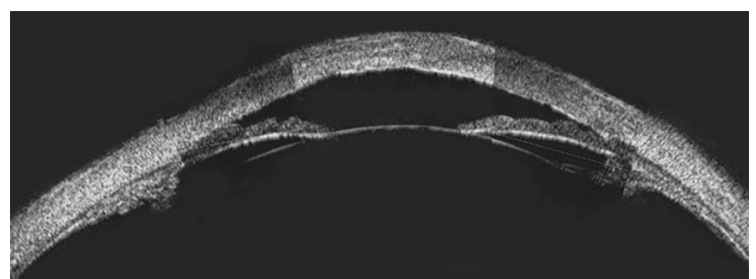

Figure 2 Ultrasound biomicroscopy image using the Humphrey-Zeiss model 840 (San Leandro, CA, USA [50 MHz]) showing a case of sclerocornea with corneal thickening, irregular morphology, and internal hyper-reflectivity.

Notes: The anterior chamber appears shallow. Reproduced with permission from Mannino G, Papale A, De Bella F. Biomicroscopia ad ultrasuoni [Ultrasound biomicroscopy]. Fabiano Editore; $2004 .^{2}$

tissue or iris hypoplasia. ${ }^{47}$ Associated ocular features include cataract, attached persistent papillary membrane strands, corectopia, glaucoma, and corneal opacification (AxenfeldRieger anomaly). ${ }^{42}$ UBM imaging can detect extremely tiny irises in all eyes with aniridia, furthermore, in eyes with aniridia a significantly smaller ciliary body length, ciliary body thickness, and iris root thickness have been shown compared to normal eyes (Figure 3). ${ }^{47}$

Marfan syndrome and Weill-Marchesani syndrome are very rare systemic diseases that are due to anomalies of connective tissue. ${ }^{48}$ The main ocular anomalies are microspherophakia, ectopia lentis, glaucoma, and myopia. UBM in the Marfan syndrome and microspherophakia shows areas where the zonules are absent and the lens is dislocated, associated with flattening of the ciliary body in the areas of missing zonules. ${ }^{48}$ Other UBM signs of spherophakia are an elongation of the zonules and an increased sphericity of the lens. Anterior zonular fibers are normally less than $1 \mathrm{~mm}$ long, while in spherophakia cases the length can be more than $2 \mathrm{~mm} .{ }^{49}$ Increased sphericity of the lens, that is associated with zonular loss or elongation, can move the iris-lens interface to a position which is anterior to the iris root causing possible pupillary block. In UBM this is shown as an anterior bowing of the iris because the pressure in the posterior chamber is higher than that of the anterior chamber. ${ }^{49}$

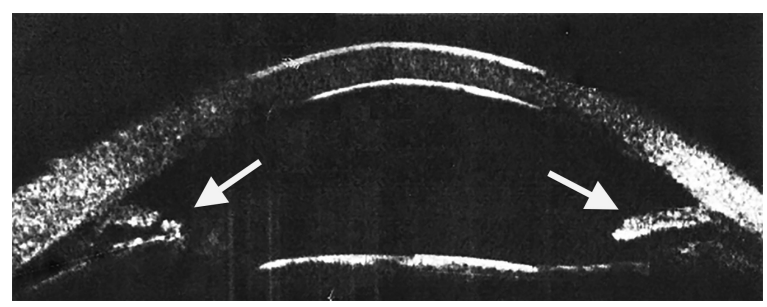

Figure 3 Ultrasound biomicroscopy image using the Humphrey-Zeiss model 840 (San Leandro, CA, USA [50 MHz]) showing an eye with aniridia.

Notes: The presence of an incomplete iris is shown with arrows. Reproduced with permission from Mannino G, Papale A, De Bella F. Biomicroscopia ad ultrasuoni [Ultrasound biomicroscopy]. Fabiano Editore; 2004. ${ }^{2}$

\section{Glaucoma in ICE syndrome}

ICE syndrome is a rare pathology characterized by corneal endothelial alterations, iris abnormalities, iridocorneal synechiae, pupillary displacement, and secondary glaucoma..$^{50-52}$ ICE syndrome is classified into three clinical sub-types: progressive iris atrophy, Cogan-Reese syndrome, and Chandler's syndrome. Various degrees of severity of iris atrophy can be detected by UBM in all forms of ICE syndrome. In mild cases, the iris is thinner than normal; in severe cases, such as in progressive iris atrophy, it can be associated with "arborised shape" of the iridocorneal angle (Figure 4). ${ }^{53,54}$ Corneal edema with Descemet layer folds is common, and clinical examination of anterior chamber may become difficult. UBM is an essential tool in the evaluation of angle changes in ICE syndrome where there is corneal edema. ${ }^{55}$ Clinical examination with both gonioscopy and UBM is useful in the characterization of peripheral anterior synechiae. Zang et al performed anterior chamber measurements with UBM which revealed peripheral anterior synechiae, and a central anterior chamber depth which was lower in patients with ICE syndrome than in normal subjects $(2.25 \pm 0.32 \mathrm{~mm}$ versus $2.76 \pm 0.32 \mathrm{~mm})$. Using UBM, these authors found that in progressive iris atrophy, peripheral anterior synechiae were less frequent, as compared to Cogan-Reese syndrome. In Chandler's syndrome, UBM showed extensive Descemet membrane folds and corneal edema with presence of peripheral anterior synechiae. ${ }^{56,57} \mathrm{In}$ any case, patients with ICE syndrome must always be periodically monitored with clinical examination including intraocular pressure measurement, gonioscopy, retina and optic nerve assessment, and visual field analysis where possible. ${ }^{58,59}$

\section{Glaucoma in phakomatoses}

Neurofibromatosis type 1 is characterized by autosomal dominant inheritance. The major ocular alterations are Lisch nodules, optic pathway gliomas, choroidal nodules, and microvascular retinal alterations. ${ }^{60-63}$ Glaucoma has been reported in $1 / 300$ afflicted patients increasing to $23 \%$ in patients with orbital-facial involvement where glaucoma is ipsilateral to the orbital-facial alterations. ${ }^{64}$

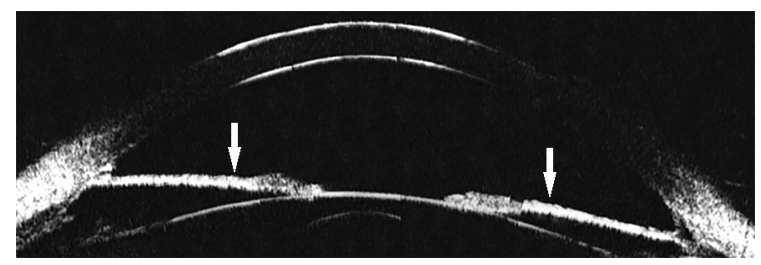

Figure 4 Ultrasound biomicroscopy image using the Humphrey-Zeiss model 840 (San Leandro, CA, USA [50 MHz]) showing essential iris atrophy. Note: The iris is thinner than normal (arrows). 
The typical anterior segment ocular features of neurofibromatosis type 1 are Lisch nodules of the iris. They are bilateral melanocytic hamartomas on the anterior surface of the iris or in the iridocorneal angle. ${ }^{60}$ Lisch nodules are detected in UBM as surface irregularities, characterized by oval or round mediumhigh reflective areas. They present a similar acoustic pattern to iris nevi. The mechanisms of glaucoma onset can be due to the presence of neurofibromas or Lisch nodules obstructing the anterior chamber, the presence of cysts, increased thickness of the ciliary body and choroid, and developmental angle abnormalities. UBM can show Lisch nodules, and abnormalities of the ciliary body and chamber angle, and help in clarifying the pathogenesis of glaucoma. ${ }^{64-66}$

The Sturge-Weber syndrome and its variants such as the Klippel-Trenaunay syndrome are frequently associated with glaucoma. In about $60 \%$ of cases with glaucoma the cause is due to anterior chamber abnormalities, which can be assessed with UBM examination, while in approximately $40 \%$ of cases of glaucoma the cause is raised episcleral venous pressure. ${ }^{67,68}$ Clinical examination and UBM in a patient with Sturge-Weber syndrome showed supraciliary effusion of 360 degrees, and dilated superficial and intrascleral vessels with an open angle supporting the hypothesis of raised episcleral venous pressure in the pathogenesis of glaucoma. ${ }^{69}$ Patients with phakomatoses and especially Sturge-Weber syndrome and its variants require routine clinical follow-up for glaucoma, which can sometimes be difficult due to the young age of patients and lack of cooperation. Visual field examination can be challenging but can improve with age and learning, and the recent advent of peripapillary retinal nerve fiber layer analysis with OCT, as an early indicator of retinal nerve fiber layer loss, can be helpful in monitoring disease..$^{70-72}$

The pathogenesis of glaucoma occurring in $10 \%$ of patients with oculodermal melanocytosis may be developmental or congenital, or associated with pigmentary changes as in melanocytic glaucoma. ${ }^{73,74}$ Phakomatosis pigmentovascularis is when oculodermal melanocytosis occurs together with the Sturge-Weber or Klippel-Trenaunay syndrome and glaucoma has been reported in all afflicted patients. ${ }^{75,76}$ The mechanism of glaucoma associated with pigment dispersion was first described by Pavlin et $\mathrm{al}^{77}$ and involves difficulty in trabecular outflow due to dispersion of pigment from the iris and is characterized by iris concavity in UBM. ${ }^{16}$

\section{Glaucoma in metabolic disorders}

Mucopolysaccharidosis, Lowe syndrome, and classical homocystinuria are rare metabolic syndromes, which can lead to secondary glaucoma. The pathogenesis of glaucoma can be congenital, or in the case of homocystinuria, can also be due to zonular abnormalities, ectopia lentis, and angle abnormalities. ${ }^{78,79}$ The use of UBM in these conditions can give detailed information on the anterior segment structures including the cornea, zonules, chamber angle, and the lens. In a case report on a rare case of mucopolysaccharidosis where corneal clouding did not allow appropriate clinical examination, UBM imaging showed corneal deposits and thickening of the corneal periphery and was fundamental in the follow-up of disease progression. ${ }^{80}$

\section{Conclusion}

UBM is a valuable imaging technique for the detailed examination of the anatomical features and structures of the anterior segment of the eye, especially in the context of opacity of the anterior structures, which can greatly limit conventional clinical examination.

In the management of glaucoma, UBM is an important tool that greatly assists the ophthalmologist in the identification of the pathologic mechanisms associated with open angle, angle closure and other sub-types of glaucoma. In glaucoma associated with rare diseases of the anterior segment, such as mesodermal dysgenesis of the neural crest, ICE syndrome, phakomatoses, and metabolic disorders, UBM is especially useful as it provides valuable information on the cornea, anterior chamber, chamber angle, iris, ciliary body, zonules, and lens, allowing a complete assessment of the ocular structures.

\section{Disclosure}

The authors report no conflicts of interest in this work.

\section{References}

1. Pavlin CJ, Foster FS. Ultrasound biomicroscopy of the eye. New York: Springer \& Verlag; 1995.

2. Mannino G, Papale A, De Bella F. Biomicroscopia ad ultrasuoni [Ultrasound biomicroscopy]. Fabiano Editore; 2004. Italian.

3. Pavlin CJ, Haraseiwicz K, Sherar MD, Foster FS. Clinical use of ultrasound biomicroscopy. Ophthalmology. 1991;98(3):287-295.

4. Ishikawa H, Schuman JS. Anterior segment imaging: ultrasound biomicroscopy. Ophthalmol Clin North Am. 2004;17(1):7-20.

5. Kiryu J, Park M, Kobayashi H, Kondo T. Ultrasound biomicroscopy of the anterior segment of newborn infants. J Pediatr Ophthalmol Strabismus. 1998;35:320-322.

6. Pavlin CJ, Harasiewicz K, Foster FS. Ultrasound biomicroscopy of anterior segment structures in normal and glaucomatous eyes. Am J Ophthalmol. 1992;113(4):381-389.

7. Pavlin CJ, Foster FS. Ultrasound biomicroscopy in glaucoma. Acta Ophthalmol Suppl. 1992;(204):7-9.

8. Cruciani F, Lorenzatti M, Nazzarro V, Abdolrahimzadeh S. Bilateral acute closure glaucoma and myopia induced by topiramate. Clin Ter. 2009; $160(3): 215-216$. 
9. Nolan W. Anterior segment imaging: ultrasound biomicroscopy and anterior segment optical coherence tomography. Curr Opin Ophthalmol. 2008;19(2):115-121.

10. Maslin JS, Barkana Y, Dorairaj SK. Anterior segment imaging in glaucoma: An updated review. Indian J Ophthalmol. 2015;63(8):630-640.

11. Marigo FA, Finger PT, McCormick SA, et al. Anterior segment implantation cysts. Ultrasound biomicroscopy with histopathologic correlation. Arch Ophthalmol. 1998;116(12):1569-1575.

12. Marigo FA, Esaki K, Finger PT, et al. Differential diagnosis of anterior segment cysts by ultrasound biomicroscopy. Ophthalmology. 1999; 106(11):2131-2135.

13. Wang BH, Yao YF. Effect of primary iris and ciliary body cyst on anterior chamber angle in patients with shallow anterior chamber. J Zhejiang Univ Sci B. 2012;13(9):723-730.

14. Mannino G, Malagola R, Abdolrahimzadeh S, Villani GM, Recupero SM. Ultrasound biomicroscopy of the peripheral retina and ciliary body in degenerative retinoschisis associated with pars plana cysts. Br J Ophthalmol. 2001;85(8):976-982.

15. Pavlin CJ, McWhae JA, McGowan HD, Foster FS. Ultrasound biomicroscopy of anterior segment tumors. Ophthalmology. 1992;99(8): $1220-1228$

16. Silverman RH. High-resolution ultrasound imaging of the eye a review. Clin Experiment Ophthalmol. 2009;37(1):54-67.

17. Fenicia V, Abdolrahimzadeh S, Mannino G, Verrilli S, Balestrieri M, Recupero SM. Intravitreal bevacizumab in the successful management of choroidal metastases secondary to lung and breast cancer unresponsive to systemic therapy: a case series. Eye (Lond). 2014;28(7): 888-891.

18. Avitabile T, Marano F, Uva MG, Reibaldi A. Evaluation of central and peripheral corneal thickness with ultrasound biomicroscopy in normal and keratoconic eyes. Cornea. 1997;16(6):639-644.

19. Reinstein DZ, Silverman RH, Coleman DJ. Very high-frequency ultrasound corneal analysis identifies anatomic correlates of optical complications of lamellar refractive surgery. Ophthalmology. 1999;106(3): 474-482.

20. Gabrieli CB, Pacella E, Abdolrahimzadeh S, Regine F, Mollo R. Excimer laser photorefractive keratectomy for high myopia and myopic astigmatism. Ophthalmic Surg Lasers. 1999;30(6):442-448.

21. Pacella E, Abdolrahimzadeh S, Balacco Gabrieli CB. Excimer laser photorefractive keratectomy for hyperopia. Ophthalmic Surg Lasers. 2001;32(1):30-34.

22. Oliveira C, Liebmann JM, Dodick JM, Topilow H, Cykiert R, Ritch R. Identification of retained nucleus fragment in the posterior chamber using ultrasound biomicroscopy. Am J Ophthalmol. 2006;141(5):964-966.

23. Lambiase A, Abdolrahimzadeh S, Recupero SM. An update on intravitreal implants in use for eye disorders. Drugs Today (Barc). 2014;50(3): 239-249.

24. Khurana RN, Appa SN, McCannel CA, et al. Dexamethasone implant anterior chamber migration: risk factors, complications, and management strategies. Ophthalmology. 2014;121(1):67-71.

25. Abdolrahimzadeh S, Plateroti P, Scarinci F, Plateroti AM. Accidental intralenticular dexamethasone intravitreal implant with the resolution of macular oedema in central retinal vein occlusion. Acta Ophthalmol. Epub 2016 Apr 29.

26. Sakata LM, Sakata K, Susann R Jr, et al. Long ciliary processes with no ciliary sulcus and appositional angle closure assessed by ultrasound biomicroscopy. J Glaucoma. 2006;15(5):371-379.

27. Aslanides IM, Libre PE, Silverman RH, et al. High frequency ultrasound imaging in pupillary block glaucoma. Br J Ophthalmol. 1995; 79(11):972-976.

28. Unsal E, Eltutar K, Muftuoglu I, Akcetin TA, Acar Y. Ultrasound biomicroscopy with unilateral pseudoexfoliation. Int J Ophthalmol. 2015; $8(4): 754-758$

29. Plateroti P, Plateroti AM, Abdolrahimzadeh S, Scuderi G. Pseudoexfoliation syndrome and pseudoexfoliation glaucoma: a review of the literature with updates on surgical management. J Ophthalmol. 2015; 2015:370371
30. Kobayashi H, Hirose M, Kobayashi K. Ultrasound biomicroscopic analysis of pseudophakic pupillary block glaucoma induced by Sommering's ring. Br J Ophthalmol. 2000;84(10):1142-1146.

31. Scuderi G, Iacovello D, Pranno F, Plateroti P, Scuderi L. Pediatric glaucoma: A literature's review and analysis of surgical results. Biomed Res Int. 2015;2015:393670.

32. Marchini G. Biometric data and pathogenesis of angle closure glaucoma. Acta Ophthalmol Scand Suppl. 2002;236:13-14.

33. Smith SD, Singh K, Lin SC, et al. Evaluation of the anterior chamber angle in glaucoma. Ophthalmology. 2013;120(10):1985-1997.

34. Dietlein TS, Engels BF, Jacobi PC, Krieglstein GK. Ultrasound biomicroscopic patterns after glaucoma surgery in congenital glaucoma. Ophthalmology. 2000;107(6):1200-1205.

35. Hussein TR, Shalby SM, Elbakary MA, Elseht RM, Gad RE. Ultrasound biomicroscopy as a diagnostic tool in infants with primary congenital glaucoma. Clin Ophthalmol. 2014;8:1725-1730.

36. Azuara-Blanco A, Spaeth GL, Araujo SV, et al. Ultrasound biomicroscopy in infantile glaucoma. Ophthalmology. 1997;104(7):1116-1119.

37. Lopez JE, Wilson RR, Alvim HS, et al. Central corneal thickness in pediatric glaucoma. J Pediatr Ophthalmol Strabismus. 2007;44(2): 112-117.

38. Tai TY, Mills MD, Beck AD, et al. Central corneal thickness and corneal diameter in patients with childhood glaucoma. J Glaucoma. 2006; 15(6):524-528.

39. Maumenee AE. The pathogenesis of congenital glaucoma: a new theory. Trans Am Ophthalmol Soc. 1958;56:507-570.

40. Barkan O. Technic of goniotomy for congenital glaucoma. Arch Ophthalmol. 1949;41:65-82.

41. Abdolrahimzadeh S, Fameli V, Mollo R, et al. Rare diseases leading to childhood glaucoma: epidemiology, pathophysiogenesis, and management. Biomed Res Int. 2015;2015:781294.

42. Tümer D, Bach-Holm D. Axenfeld-Rieger syndrome and spectrum of PITX2 and FOXC1 mutations. Eur J Hum Genet. 2009;17(12): 1527-1539.

43. Contestabile MT, Plateroti R, Galasso C, Abodolrahimzadeh S, Delorenzi G, Rosa F. Peters' anomaly associated with central spastic palsy. J Pediatr Ophthalmol Strabismus. 1995;32(6):395-396.

44. Ito YA, Walter MA. Genomics and anterior segment dysgenesis: a review. Clin Experiment Ophthalmol. 2014;42(1):13-24.

45. Neuhaus C, Betz C, Bergmann C, Boltz HJ. Genetic der kongenitalen Aniridie [Genetics of congenital aniridia]. Ophthalmologe. 2014;111(12):1157-1163. German.

46. Okamoto F, Nakano S, Okamoto C, Hommura S, Oshika T. Ultrasound biomicroscopic findings in aniridia. Am J Ophthalmol. 2004;137(5): $858-862$.

47. Lee HJ, Colby KA. A review of the clinical and genetic aspects of aniridia. Semin Ophthalmol. 2013;28:306-312.

48. Chu BS. Weill-Marchesani syndrome with glaucoma and ectopia lentis. Clin Exp Optom. 2006;89(2):95-99.

49. Pavlin CJ, Buys YM, Pathmanathan T. Imaging zonular abnormalities using ultrasound biomicroscopy. Arch Ophthalmol. 1998;116(7): 854-857.

50. Agard E, Malcles A, El Chehab H, et al. L'iridoschisis, une forme particulière d'atrophie irienne [Iridoschisis, a special form of iris atrophy]. J Fr Ophtalmol. 2013;36(4):368-371. French.

51. Shields MB. Progressive essential iris atrophy, Chandler's syndrome, and the iris nevus (Cogan-Reese) syndrome: a spectrum of disease. Surv Ophthalmol. 1979;24(1):3-20.

52. Laganowski HC, Kerr Muir MG, Hitchings RA. Glaucoma and the iridocorneal endothelial syndrome. Arch Ophthalmol. 1992;110(3): 346-350.

53. Townsend WM. Congenital corneal leukomas. 1. Central defect in Descemet's membrane. Am J Ophthalmol. 1974;77(1):80-86.

54. Offret H, Saraux H, Pouliquen Y, Dhermy P. Syndrome de non disconction du cristallin. Etude anatomo-clinique et ultrastructurale (A propos de trois cas) [Congenital leukomas with anomalies of the lens migration (author's trans1)]. J Fr Ophthalmol. 1978;1(8-9):517-527. French. 
55. Dada T, Gadia R, Sharma A, et al. Ultrasound biomicroscopy in glaucoma. Survey of Ophthalmology. 2011;56(5):433-450.

56. Zhang MI, Chen J, Liang L, Laties AM, Liu Z. Ultrasound biomicroscopy of Chinese eyes with iridocorneal endothelial syndrome. Br J Ophthalmol. 2006;90(1):64-69.

57. Townsend WM, Font RL, Zimmerman LE. Congenital corneal leukomas 2. Histopathologic findings in 19 eyes with central defect in Descemet's membrane. Am J Ophthalmol. 1974;77(2):192-206.

58. Recupero SM, Contestabile MT, Taverniti L, Villani GM, Recupero V. Open-angle glaucoma: variations in the intraocular pressure after visual field examination. J Glaucoma. 2003;12(2):114-118.

59. Iester M, Perdicci A, Capris E, Siniscalco A, Calabria G, Recupero SM. Comparison between discriminant analysis models and glaucoma probability score for the detection of glaucomatous optic nerve head changes. J Glaucoma. 2008;17(7):535-540.

60. Recupero SM, Plateroti R, Abdolrahimzadeh S, Calvieri S. Lisch nodules in neurofibromatosis type 1. Relationship to age and cutaneous neurofibromas. Annals of Ophthalmology - Glaucoma. 1996;28(3): 178-183.

61. Abdolrahimzadeh S, Felli L, Plateroti R, et al. Morphologic and vasculature features of the choroid and associated choroid-retinal thickness alterations in neurofibromatosis type 1. Br J Ophthalmol. 2015;99(6):789-793

62. Listernick R, Ferner RE, Liu GT, Gutmann DH. Optic pathway gliomas in neurofibromatosis-1: controversies and recommendations. Ann Neurol. 2007;61(3):189-198.

63. Abdolrahimzadeh S, Felli L, Piraino DC, et al. Retinal microvascular abnormalities overlying choroidal nodules in neurofibromatosis type 1 BMC Ophthalmol. 2014;14:146.

64. Morales J, Chaudhry IA, Bosley TM. Glaucoma and globe enlargement associated with neurofibromatosis type 1. Ophthalmology. 2009; 116(9):1725-1730.

65. Grant WM, Walton DS. Distinctive gonioscopic findings in glaucoma due to neurofibromatosis. Arch Ophthalmol. 1968;79(2):127-134

66. Mantelli F, Abdolrahimzadeh S, Mannino G, Lambiase A. Unusual case of angle closure glaucoma in a patient with neurofibromatosis type 1 . Case Rep Ophthalmol. 2014;5(3):386-391.

67. Lambiase A, Mantelli F, Mannino G, Recupero SM. An unusual case of acute glaucoma in Sturge-Weber syndrome. Eur J Ophthalmol. 2015;25(6):e103-e105.
68. Abdolrahimzadeh S, Scavella V, Felli L, et al. Ophthalmic alterations in the Sturge Weber syndrome, Klippel Trenaunay syndrome and the phakomatosis pigmentovascularis: an independent group of conditions? Biomed Res Int. 2015;2015:786519.

69. Kranemann CE, Pavlin CJ, Trope GE. Ultrasound biomicroscopy in Sturge-Weber-associated glaucoma. Am J Ophthalmol. 1998; 125(1):119-121.

70. Contestabile MT, Perdicchi A, Amodeo S, Recupero V, Recupero SM. The influence of learning effect on frequency doubling technology perimetry (Matrix). J Glaucoma. 2007;16(3):297-301.

71. Patel DE, Cumberland PM, Walters BC, et al. Study of optimal perimetric testing in children (OPTIC): normative visual field values in children. Ophthalmology. 2015;122(8):1711-1717.

72. Abdolrahimzadeh S, Felli L, Plateroti AM, Perdicchi A, Contestabile MT, Recupero SM. Spectral domain optical coherence tomography evidence of retinal nerve fibre layer and ganglion cell loss in adult patients with neurofibromatosis type 1. Retina. 2016;36(1): $75-81$.

73. Gonder JR, Nichol J, Augsburger JJ, Shields JA. Ocular and oculodermal melanocytosis. Can J Ophthalmol. 1985;20(5):176-178.

74. Teekhasaenee C, Ritch R, Rutnin U, Leelawongs N. Glaucoma in oculodermal melanocytosis. Ophthalmology. 1990;97(5):562-570.

75. Teekhasaenee C, Ritch R. Glaucoma in phakomatosis pigmentovascularis. Ophthalmology. 1997;104(1):150-157.

76. Recupero SM, Abdolrahimzadeh S, De Dominicis M, Mollo R. SturgeWeber Syndrome associated with nevus of Ota. Eye (Lond). 1998; 12(Pt 2):212-213.

77. Pavlin CJ, Macken P, Trope GE, Harasiewicz K, Foster FS. Accommodation and iridotomy in the pigment dispersion syndrome. Ophthalmic Surg Lasers. 1996;27(2):113-120.

78. Walton DS, Katsavounidou G, Lowe CU. Glaucoma with the oculocerebrorenal syndrome of Lowe. J Glaucoma. 2005;14(3):181-185.

79. Ashworth J, Flaherty M, Pitz S, Ramlee A. Assessment and diagnosis of suspected glaucoma in patients with mucopolysaccharidosis. Acta Ophthalmol. 2015;93(2):e111-e117.

80. Casanova FH, Adan CB, Allemann N, de Freitas D. Findings in the anterior segment on ultrasound biomicroscopy in Maroteaux-Lamy syndrome. Cornea. 2001;20(3):333-338.
Clinical Ophthalmology

\section{Publish your work in this journal}

Clinical Ophthalmology is an international, peer-reviewed journal covering all subspecialties within ophthalmology. Key topics include: Optometry; Visual science; Pharmacology and drug therapy in eye diseases; Basic Sciences; Primary and Secondary eye care; Patient Safety and Quality of Care Improvements. This journal is indexed on

\section{Dovepress}

PubMed Central and CAS, and is the official journal of The Society of Clinical Ophthalmology (SCO). The manuscript management system is completely online and includes a very quick and fair peer-review system, which is all easy to use. Visit http://www.dovepress.com/ testimonials.php to read real quotes from published authors. 